\title{
Glucocorticoids Increase Renal Excretion of Urate in Mice by Downregulating Urate Transporter $1^{\text {零 }}$
}

\author{
Gentao Li, Lifeng Han, Ruicong Ma, Khawar Saeed, Hui Xiong, Curtis D. Klaassen, Yuanfu Lu, \\ and Youcai Zhang
}

School of Pharmaceutical Science and Technology, Tianjin University (G.L., R.M., K.S., H.X., Y.Z.), and Tianjin State Key Laboratory of Modern Chinese Medicine, Tianjin Key Laboratory of TCM Chemistry and Analysis, Tianjin University of Traditional Chinese Medicine, Nankai District (L.H.), Tianjin, China; Department of Environmental and Occupational Health Sciences, University of

Washington, Seattle, Washington (C.D.K.); and Key Laboratory of Basic Pharmacology of Ministry of Education and Joint International Research Laboratory of Ethnomedicine of Ministry of Education, Zunyi Medical University, Zunyi, Guizhou, China (Y.L.)

Received May 3, 2019; accepted August 20, 2019

\begin{abstract}
Both nonsteroidal anti-inflammatory drugs (NSAIDs) and glucocorticoids have been widely used for the treatment of gout, a disease promoted by an excess body burden of uric acid (UA); however, their effects on the homeostasis of UA remain poorly understood. The present study showed that 1 -week treatments with three NSAIDs (ibuprofen, diclofenac, and indomethacin) had little effect on UA homeostasis in mice, whereas 1-week low doses ( 1 and $5 \mathrm{mg} / \mathrm{kg}$ ) of dexamethasone (DEX) significantly decreased serum UA by about $15 \%$. Additionally, low doses of DEX also resulted in increases in hepatic UA concentration and urinary UA excretion, which were associated with an induction of xanthine oxidoreductase (XOR) in the liver and a downregulation of urate transporter 1 (URAT1) in the kidney, respectively. Neither $75 \mathrm{mg} / \mathrm{kg}$ DEX nor $100 \mathrm{mg} / \mathrm{kg}$ pregnenolone-16 $\alpha$-carbonitrile altered UA concentrations in serum and livers of mice, suggesting that the
\end{abstract}

effect of DEX on UA homeostasis was not due to the pregnane $X$ receptor pathway. Further in vitro studies demonstrated that glucocorticoid receptor (GR) was involved in DEX-mediated downregulation of URAT1. Knockdown of both p65 and c-Jun completely blocked the effect of DEX on URAT1, suggesting that GR regulates URAT1 via its interaction with both nuclear factor $\kappa B$ and activator protein 1 signaling pathways. To conclude, the present study identifies, for the first time, a critical role of glucocorticoids in regulating UA homeostasis and elucidates the mechanism for GR-mediated regulation of URAT1 in mice.

\section{SIGNIFICANCE STATEMENT}

This study demonstrates, for the first time, a critical role of glucocorticoid receptor in regulating urate transporter 1 in mouse kidney.

\section{Introduction}

Gout, a chronic disease triggered by the deposition of monosodium urate crystals in the joints, has become the most common type of inflammatory arthropathy in adults, with a general prevalence of $1 \%-4 \%$ (Dalbeth et al., 2016). The central pathologic feature of gout is the elevated concentrations of serum uric acid (UA), also known as hyperuricemia, caused by an imbalance of UA production and elimination from the body. UA is synthesized mainly in the liver

This work was supported by the open project from the Key Laboratory of Basic Pharmacology of Ministry of Education at Zunyi Medical University [Grant no. 2014-5]. This work was also supported by grants from the National Natural Science Foundation of China [Grants no. 81673523 and no. 81703834], and the Project of National Basic Research (973) Program of China [Grant no. 2015CB856504].

https://doi.org/10.1124/dmd.119.087700.

SThis article has supplemental material available at dmd.aspetjournals.org. during the metabolism of both endogenous (DNA, RNA, and ATP) and exogenous (dietary) purines. Xanthine oxidoreductase (XOR), which exists in the form of either xanthine dehydrogenase (XDH) or xanthine oxidase (XOD), regulates the rate-limiting step, catalyzing the conversion from hypoxanthine to xanthine and from xanthine to UA (Maiuolo et al., 2016). It should be noted that UA is the final product of purines in humans, whereas it is further converted to more soluble allantoin by uricase in most other species (Kratzer et al., 2014).

Elimination of UA occurs via two major routes, with approximately $70 \%$ excreted through the kidney and the remaining 30\% through the intestine (Sorensen, 1965). UA in the circulation is freely filtered at the glomeruli, and about $90 \%$ of the filtered UA is reabsorbed into the blood (Mount, 2005). Various transporters are involved in the UA disposition in the kidney. Among them, urate transporter 1 (URAT1), a urate/anion exchanger at the apical membrane of the proximal tubule, is one of the two most critical transporters for renal reabsorption of UA. The association between URAT1 and hyperuricemia has been widely established in many genetic studies (Tin et al., 2018). In contrast,

ABBREVIATIONS: BCRP, breast cancer resistance protein; DEX, dexamethasone; DIC, diclofenac; DMEM, Dulbecco's modified Eagle's medium; FBS, fetal bovine serum; GR, glucocorticoid receptor; HPLC, high-performance liquid chromatography; IBU, ibuprofen; INDO, indomethacin; MIF, mifepristone; Mrp4, multidrug resistance protein 4; Npt, sodium-dependent phosphate cotransporter; NRK, normal rat kidney epithelial cells; NSAIDs, nonsteroidal anti-inflammatory drugs; Oat, organic anion transporter; PCN, pregnenolone-16 $\alpha$-carbonitrile; PXR, pregnane X receptor; siRNA, small interfering RNA; TA, triamcinolone acetonide; UA, uric acid; URAT1, urate transporter 1 ; XDH, xanthine dehydrogenase; XOD, xanthine oxidase; XOR, xanthine oxidoreductase. 

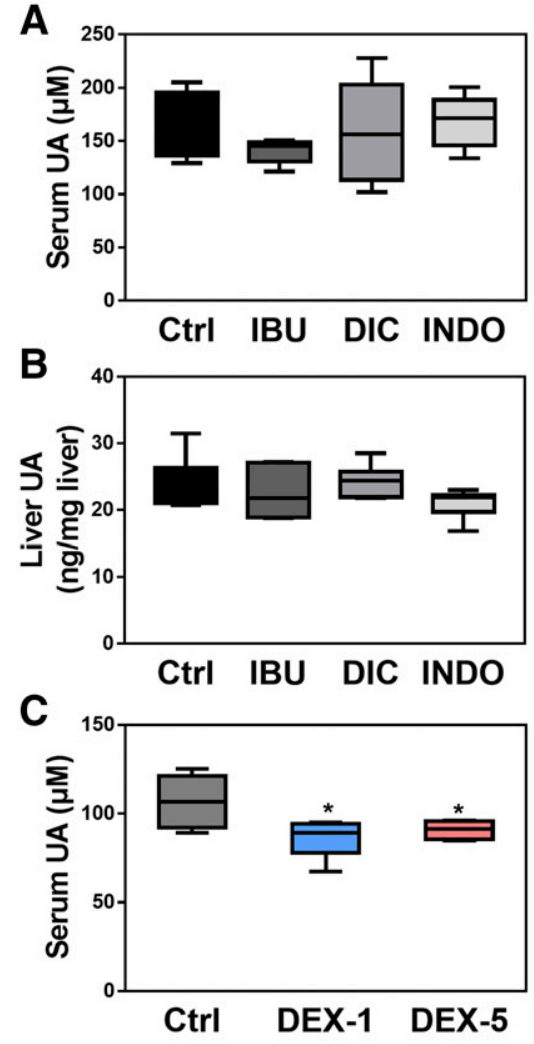
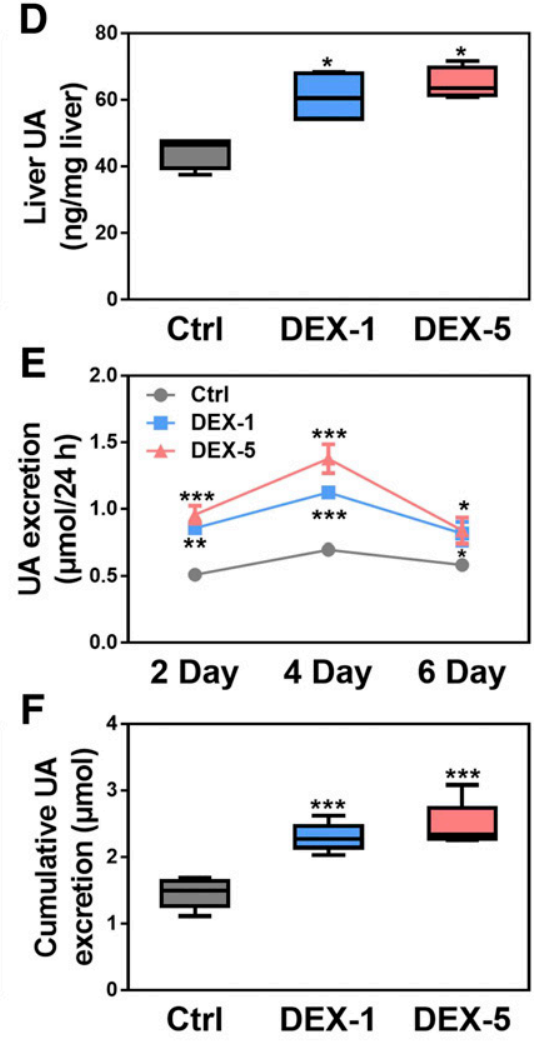

Fig. 1. DEX, but not NSAIDs, markedly alter UA homeostasis in mice. Male C57/BL6 mice ( $n=5 /$ group) were administered NSAIDs ( $30 \mathrm{mg} / \mathrm{kg}$ IBU, $5 \mathrm{mg} / \mathrm{kg}$ DIC, and $2.5 \mathrm{mg} / \mathrm{kg}$ INDO, p.o.) or DEX (1 and $5 \mathrm{mg} / \mathrm{kg}$, i.p.) for 7 days. The UA concentrations were quantified in the serum and livers of mice treated with either NSAIDs (A and B) or DEX (C and D). Urine from DEX-treated mice were collected on the 2 nd, 4 th, and 6 th days, respectively. The urine volume for each 24-hour period was measured. UA concentrations in the urine were quantified, and urinary excretion of UA was calculated for 24-hour periods (E). The total UA in the urine over 3 days was also calculated (F). Data are expressed as mean \pm S.E.M. $(n=5) .{ }^{*} P<0.05$ versus control (Ctrl) group; $* * * P<0.001$ vs. Ctrl group. studies on the regulation of URAT1 are quite limited. URAT1 has been reported to be regulated by insulin and $\alpha$ kinase 1 (Kuo et al., 2017; Toyoki et al., 2017). Nonetheless, the exact regulatory mechanisms of URAT1 expression remain elusive.

Both nonsteroidal anti-inflammatory drugs (NSAIDs) and steroids have been widely used for pain relief and inflammation suppression during an acute gout attack (Ragab et al., 2017). Aspirin was reported to alter the renal excretion of UA by either cis- or trans-inhibition of URAT1 (Enomoto et al., 2002; Zhang et al., 2014). Glucocorticoids, such as dexamethasone (DEX), increase xanthine oxidase activity in rats (Patel et al., 2014). Nevertheless, the effect of glucocorticoids and NSAIDs other than aspirin on UA homeostasis is largely unknown. The present study aimed to investigate systematically the effect of NSAIDs and DEX on UA homeostasis.

\section{Materials and Methods}

Chemical Reagents. DEX, UA, XOD, and pregnenolone-16 $\alpha$-carbonitrile (PCN) were purchased from Sigma-Aldrich (St. Louis, MO). Triamcinolone acetonide (TA) was obtained from Energy Chemical (Shanghai, China), and mifepristone (MIF) was purchased from Macklin (Shanghai, China). Ibuprofen (IBU), diclofenac (DIC), and indomethacin (INDO) were purchased from Alfa Aesar (Ward Hill, UK). All other chemicals were commercial products of the highest purity grade available.

Animals and Treatments. All animal studies were carried out at the Institute of Radiation Medicine of the Chinese Academy of Medical Sciences (CAMS, Tianjin, China) and approved by the Institutional Animal Care and Use Committee at the CAMS. Adult male C57/BL6 (20 $\pm 2 \mathrm{~g})$ mice were purchased from Beijing Vital River Laboratory Animal Technology Co., Ltd (Beijing, China). Mice were housed in an environmentally controlled breeding room (temperature: $22 \pm 2{ }^{\circ} \mathrm{C}$, humidity: $55 \% \pm 5 \%$, and 12 -hour light/dark cycle) and water ad libitum.

IBU has been recommended for use as a pain reliever in mice, with a ranging dose of 7.5-30 mg/kg (Jenkins, 1987; Liles and Flecknell, 1992). In this study, we chose the maximal recommended dose of IBU $(30 \mathrm{mg} / \mathrm{kg})$. Previous studies in mice suggested that oral treatments with $2.5-5 \mathrm{mg} / \mathrm{kg}$ DIC or $1 \mathrm{mg} / \mathrm{kg}$ INDO sufficed to exert their anti-inflammation and analgesic effects in mice (Fujiyoshi et al., 1989; Mun et al., 2009; Ritesh et al., 2016); however, $10 \mathrm{mg} / \mathrm{kg}$ DIC or INDO induced marked adverse effects in the gastrointestinal tract of mice (Harusato et al., 2009; Yamada et al., 2011; Akingbasote et al., 2016; Xiao et al., 2017). In our preliminary study, mice were orally gavaged with DIC (5 and $10 \mathrm{mg} / \mathrm{kg})$ or INDO $(2.5$ and $7.5 \mathrm{mg} / \mathrm{kg})$ to evaluate their potential toxicities. The data showed that both $10 \mathrm{mg} / \mathrm{kg}$ DIC and $7.5 \mathrm{mg} / \mathrm{kg}$ INDO markedly decreased body weights and increased liver and spleen weights (as determined via the tissue/body-weight ratios), with marked alterations in liver and intestine morphology (Supplemental Fig. 1). In contrast, both $5 \mathrm{mg} / \mathrm{kg}$ DIC and $2.5 \mathrm{mg} / \mathrm{kg}$ INDO were well tolerated by mice. Therefore, we chose $5 \mathrm{mg} / \mathrm{kg}$ DIC and $2.5 \mathrm{mg} / \mathrm{kg}$ INDO for the present study. Additionally, several NSAIDs are reported to regulate the expression of a target gene, namely, NSAID-activated gene-1 (NAG-1), which plays an important role in cell growth and proliferation (Kim et al., 2002). As shown in Supplemental Fig. 2, the mRNA expression of NAG-1 was induced in livers of mice treated with $30 \mathrm{mg} / \mathrm{kg}$ IBU, $5 \mathrm{mg} / \mathrm{kg}$ DIC, and $2.5 \mathrm{mg} / \mathrm{kg}$ INDO (Supplemental Fig. 2). Therefore, our data suggest that the dose of each NSAID suffices to exert its therapeutic effect and is relatively close to the maximum nontoxic dose. Mice were randomly divided into four groups $(n=5)$ : control, IBU (30 mg/kg, p.o.), DIC $(5 \mathrm{mg} / \mathrm{kg}$, p.o.), and INDO (2.5 mg/kg, p.o.). The doses and schedules of NSAIDs were selected according to the previous studies (Wang et al., 1994; Klopcic et al., 2008; Akingbasote et al., 2016). NSAIDs were dissolved in sterile saline containing $0.25 \%$ sodium carboxymethylcellulose and $0.5 \%$ Tween80. Mice were treated orally with NSAIDs once daily for 7 days. To investigate the effects of DEX on UA homeostasis, mice were treated with DEX at either 1 or $5 \mathrm{mg} / \mathrm{kg}$ (DEX-1 and DEX-5) i.p. for 7 days. DEX was dissolved in sterile saline containing $10 \%$ PEG400. To determine the effect of pregnane $\mathrm{X}$ receptor (PXR) activation on UA homeostasis, mice were treated intraperitoneally with either DEX (75 mg/kg; DEX-75) or PCN (100 mg/kg) for 4 days. The vehicle control for the high-dose DEX and PCN was corn oil.

Urine and Tissue Sample Collection. Urine was collected for three 24-hour periods on 2nd, 4th, and 6th day from each mouse using individual metabolic 


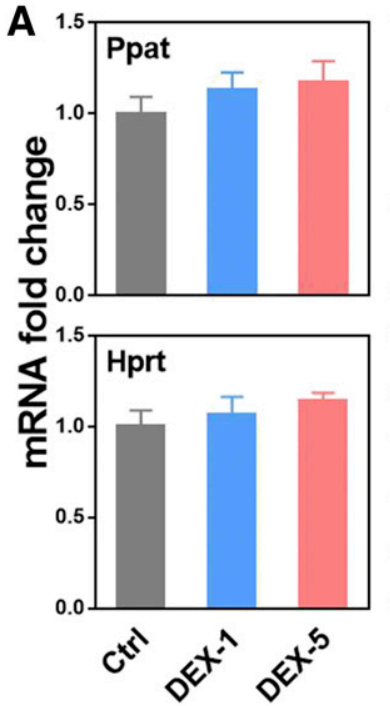

B

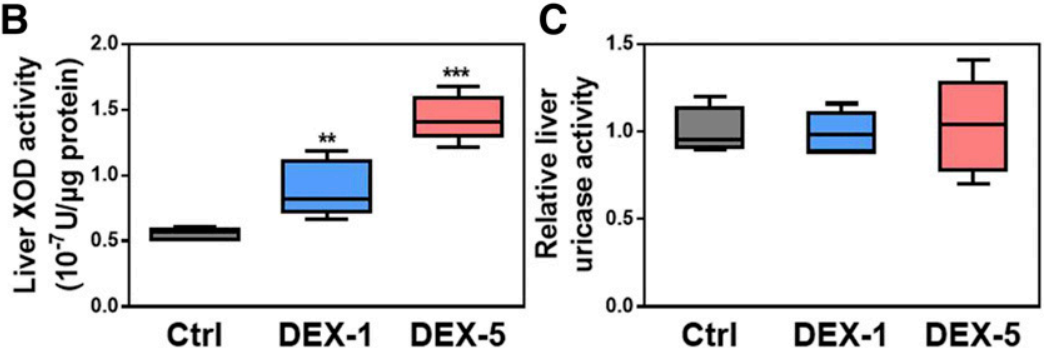

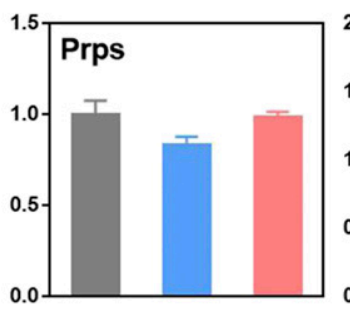
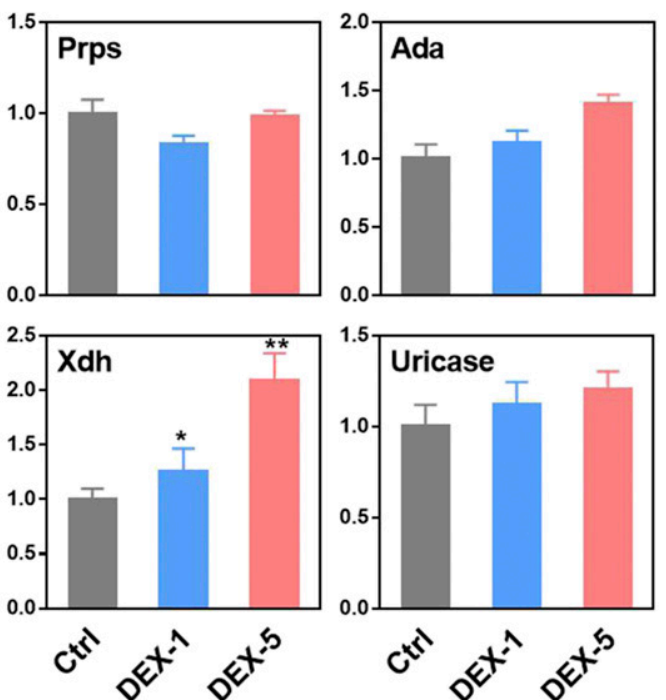

Fig. 2. DEX increased UA synthesis in livers of mice via XOD induction. Male C57/BL6 mice ( $n=5$ /group) were administered DEX (1 and $5 \mathrm{mg} / \mathrm{kg}$, i.p.) for 7 days. The mRNA levels of phosphoribosyl amidotransferase (Ppat), phosphoribosyl pyrophosphate synthetase (Prps), adenosine deaminase (Ada), hypoxanthineguanine phosphoribosyltransferase (Hprt), XDH, and uricase (A) in the livers of mice were quantified using RT-PCR. The activities of XOD (B) and uricase (C) were quantified in the livers of mice. Data are expressed as mean \pm S.E.M. $(n=5)$. ${ }^{*} P<0.05$ vs. control (Ctrl) group; $* * P<0.01$ vs. Ctrl) group; $* * * P<0.001$ vs. Ctrl group. cages. Urine samples were centrifuged at $3000 \mathrm{~g}$ at $4^{\circ} \mathrm{C}$ for 10 minutes to collect the supernatants for further analysis. On the last day of the study, blood was collected by orbital bleeding 1 hour after the corresponding administrations and centrifuged at $5000 \mathrm{~g}$ at $4^{\circ} \mathrm{C}$ for 20 minutes to obtain serum. Kidneys and livers were harvested, rinsed, snap-frozen in liquid nitrogen, and stored at $-80^{\circ} \mathrm{C}$.
Quantification of UA. Serum and urine UA concentrations were quantified using a standard diagnostic kit (Jiancheng Bioengineering Institute, Nanjing, China) according to the manufacturer's instructions. Liver UA concentration was quantified using high-performance liquid chromatography (HPLC) analysis. Briefly, liver tissue was homogenized in two volumes of $\mathrm{ddH}_{2} \mathrm{O}$, and $40 \mu \mathrm{l}$ of
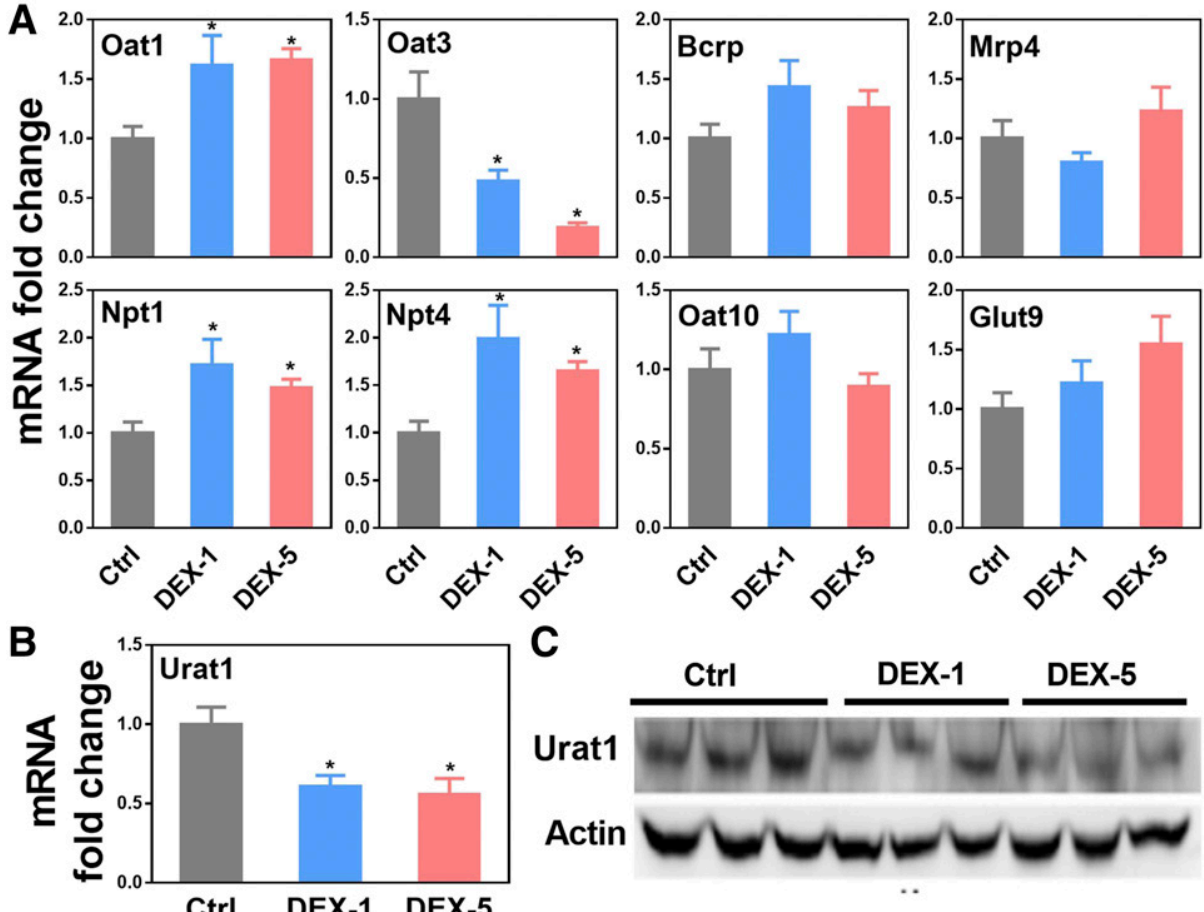

C

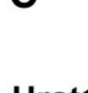

Ctrl

DEX-1

DEX-5

Ctrl

\section{Actin}

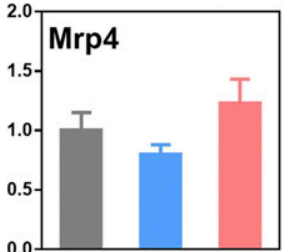

Fig. 3. DEX decreased both $\mathrm{mRNA}$ and protein levels of URAT1 in kidneys of mice. Male C57/BL6 mice ( $n=5$ /group) were administered DEX (1 and $5 \mathrm{mg} / \mathrm{kg}$, i.p.) for 7 days. The mRNA levels of Oat1, Oat3, BCRP, Mrp4, Npt1, Npt4, Oat10, and Glut9 (A) were quantified in the kidneys of mice. The mRNA (B) and protein levels (C) of URAT1 in kidneys of mice were quantified using RT-PCR and Western blot, respectively. Data are expressed as mean \pm S.E.M. $(n=5) . * P<0.05$ vs. control (Ctrl) group. 
A
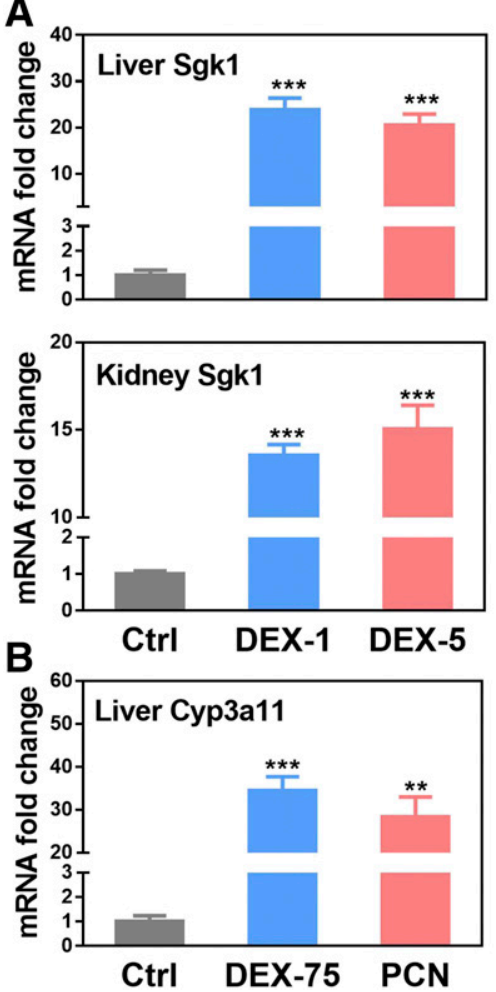

C

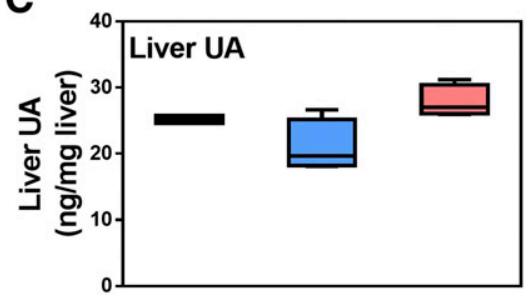

D
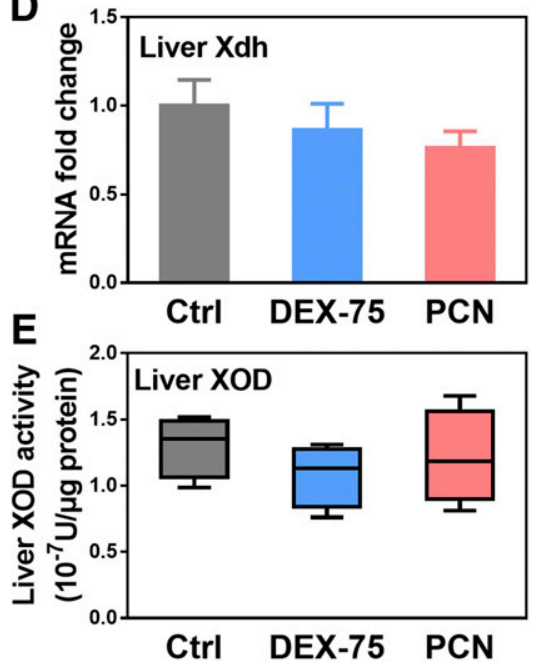

Fig. 4. DEX-mediated regulation of UA homeostasis was not due to PXR signaling pathway. Male C57/BL6 mice ( $n=5$ /group) were administered DEX (1 and $5 \mathrm{mg} / \mathrm{kg}$, i.p.) for 7 days. The mRNA expression of Sgk1 was quantified in the livers and kidneys (A) of mice. Male C57/BL6 mice ( $n=5 /$ group) were administered either $75 \mathrm{mg} / \mathrm{kg}$ DEX or $100 \mathrm{mg} / \mathrm{kg}$ PCN for 4 days. The mRNA levels of Cyp3a11 (B) and XDH (D) were quantified in the livers of mice. UA concentrations in the livers of mice were quantified (C), and the XOD activities were also measured (E). Data are expressed as mean \pm S.E.M. $(n=5)$. $* * P<0.01$ vs. control $(\mathrm{Ctrl})$ group; $* * * P<$ 0.001 vs. control $(\mathrm{Ctrl})$ group. homogenate was gently mixed with $120 \mu \mathrm{l}$ of $0.2 \mathrm{M}$ perchloric acid containing 1,3-dimethyl uric acid $(40 \mu \mathrm{M})$ as the internal standard. The mixture was centrifuged at $20,000 \mathrm{~g}$ for 10 minutes, and $20 \mu \mathrm{l}$ of the supernatant was injected for HPLC analysis. HPLC was performed on an Agilent 1260 Infinity II with a Zorbax SB-C18 $(2.1 \times 150 \mathrm{~mm}, 5 \mu \mathrm{m})$ column (Agilent Technologies, Santa Clara, CA). Mobile phase A contained $0.1 \%$ formic acid, and mobile phase $\mathrm{B}$ was acetonitrile. The entire process of separation was done on a gradient elution at a flow rate of $0.5 \mathrm{ml} / \mathrm{min}$ for 15 minutes: initiated with $8 \%$ B for 2 minutes, increased to $20 \%$ B in 1 minute, and further increased to $90 \%$ B in 7 minutes, kept $90 \%$ B for 1 minute, decreased to $8 \%$ B in 1 minute, and balanced for 3 minutes before the next injection. Before the injection, the needle was washed with $50 \%$ methanol for 5 seconds, and the injection volume was $20 \mu$ l. Detection wavelength for UA was $294 \mathrm{~nm}$ (Tsushima et al., 2013).

Assays for XOD and Uricase Activities. Liver tissue was homogenized in 9 volumes of $50 \mathrm{mM} \mathrm{KH}_{2} \mathrm{PO}_{4}$ buffer containing $0.5 \mathrm{mM}$ EDTA (pH 7.4) in an ice bath. The homogenate was centrifuged at $4000 \mathrm{~g}$ for 20 minutes at $4^{\circ} \mathrm{C}$, and the lipid layer was carefully discarded. The supernatant was further centrifuged at
A

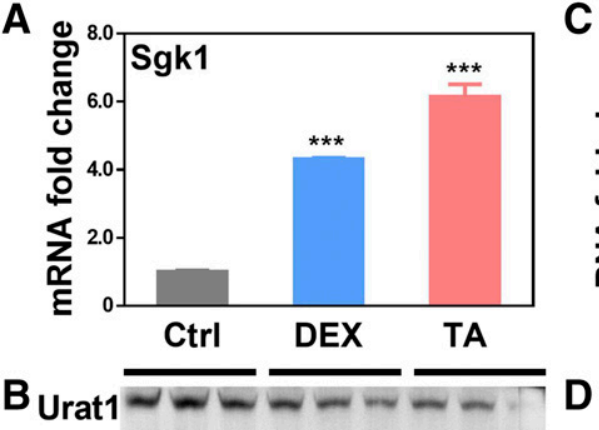

Actin $-\infty=-\infty=\square$

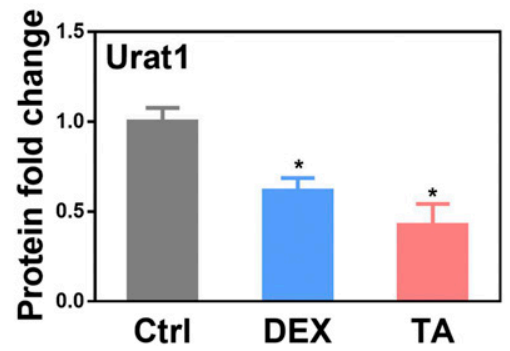

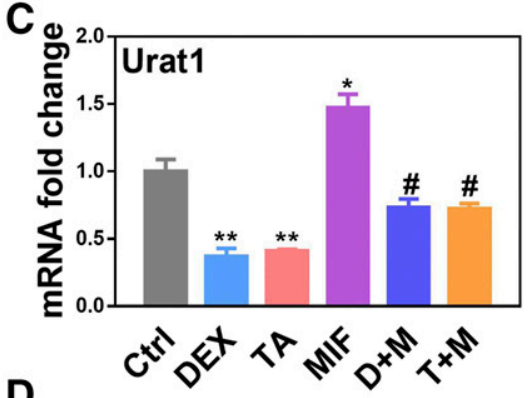

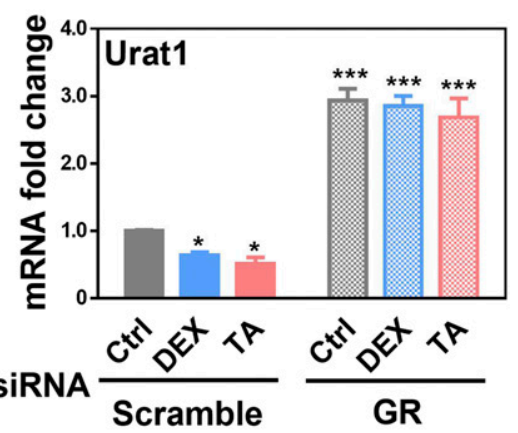

Fig. 5. GR-regulated DEX-mediated downregulation of URAT1 in vitro. NRK-52E cells were incubated DEX, TA, and MIF at $1,0.5$, and $0.15 \mu \mathrm{M}$, respectively. Cells were harvested after either 24 hours for RNA isolation or 48 hours for protein extraction. The mRNA levels of Sgk1 (A) and URAT1 (C) were quantified using RT-PCR. The protein levels of URAT1 (B) were determined using Western blot. To determine more fully the role of GR, scramble control and GR-specific siRNAs were transfected into NRK-52E cells using LipofectAMINE RNAiMAX. After 24 hours of siRNA transfection, scramble control and GR-knockdown NRK-52E cells were incubated with $1 \mu \mathrm{M}$ DEX or $0.5 \mu \mathrm{M}$ TA for additional 24 hours. The mRNA levels of URAT1 were quantified using RT-PCR (D). D + M stands for the combination treatment of DEX and MIF, whereas $\mathrm{T}+\mathrm{M}$ is the combination treatment of TA and MIF. Data are expressed as mean \pm S.E.M.; $* P<0.05$ versus control (Ctrl) group; ${ }^{* *} P<0.01$ vs. control (Ctrl) group, *** $P<0.001$ vs. control (Ctrl) group. ${ }^{\#} P<0.05$ for $\mathrm{D}+\mathrm{M}$ vs. DEX, and $\mathrm{T}+\mathrm{M}$ vs. TA. 
TABLE 1

In silico analysis of the urate transporter 1 (URAT1) promoter

The promoters were analyzed using the AliBaba2.1 search tool (http://gene-regulation.com/ pub/programs/alibaba2/index.html) using default parameters: pairism to known sites 50, matrix width $10 \mathrm{bp}$, minimum number of sites 4 , minimum matrix conservation $75 \%$, similarity to sequence matrix $1 \%$, factor class level 4 .

\begin{tabular}{|c|c|c|}
\hline Species & Predicted Elements & Nucleotide Positions \\
\hline \multirow[t]{9}{*}{ Human } & AP-1 & $407-416$ \\
\hline & & $908-917$ \\
\hline & & 967-976 \\
\hline & & $1154-1163$ \\
\hline & & $1682-1693$ \\
\hline & & 1873-1882 \\
\hline & $\mathrm{NF}-\kappa \mathrm{B}$ & -353 to 362 \\
\hline & & -548 to 557 \\
\hline & & -1889 to 1898 \\
\hline \multirow[t]{15}{*}{ Mouse } & AP-1 & $69-78$ \\
\hline & & $137-146$ \\
\hline & & $302-311$ \\
\hline & & $325-334$ \\
\hline & & $547-556$ \\
\hline & & $632-644$ \\
\hline & & $667-676$ \\
\hline & & $1373-1382$ \\
\hline & & $1597-1606$ \\
\hline & & $1750-1759$ \\
\hline & & 2021-2030 \\
\hline & $\mathrm{NF}-\kappa \mathrm{B}$ & $265-274$ \\
\hline & & 957-966 \\
\hline & & $1638-1647$ \\
\hline & & $2794-2803$ \\
\hline \multirow[t]{14}{*}{ Rat } & AP-1 & $138-147$ \\
\hline & & $239-248$ \\
\hline & & $303-312$ \\
\hline & & $326-335$ \\
\hline & & $562-571$ \\
\hline & & $893-902$ \\
\hline & & 926-935 \\
\hline & & $1247-1256$ \\
\hline & & $1683-1695$ \\
\hline & & $1733-1742$ \\
\hline & & 1996-2005 \\
\hline & & $2100-2109$ \\
\hline & $\mathrm{NF}-\kappa \mathrm{B}$ & $2402-2411$ \\
\hline & & $2752-2761$ \\
\hline
\end{tabular}

AP-1, activator protein 1 ; NF- $\kappa$, nuclear factor $\kappa$. et al., 1998). Cells were harvested either 24 hours (RNA isolation) or 48 hours (protein extraction) later for further analysis.

Gene Silencing with Small Interfering RNAs. Small interfering RNAs (siRNAs) were synthesized by Genepharma (Suzhou, China). siRNAs were designed according to previous studies, and the sequences were listed in Supplemental Table 1 (Numakawa et al., 2009; Sirabella et al., 2009; Ban et al., 2011). siRNAs were transfected into NRK-52E cells using LipofectAMINE RNAiMAX (Invitrogen, Carlsbad, CA) according to the manufacturer's protocol. Briefly, about 12-24 pmol siRNAs and $1 \mu \mathrm{l}$ of LipofectAMINE were diluted in $100 \mu \mathrm{l}$ of Opti-MEM, mixed gently, and then incubated for 20 minutes at room temperature. The entire mixture was added to the well of a 24-well plate, and then NRK-52E cells were seeded at a density of $2.5 \times 10^{5} /$ well in DMEM medium with $5 \%$ FBS. The mixture was incubated with cells for 24 hours, followed by various treatments for indicated time periods.

RNA Isolation and Quantitative Reverse Transcription Polymerase Chain Reaction Analysis. Messenger RNA (mRNA) was isolated using Trizol (Takara, Dalian, China) according to the manufacturer's protocol. After isolation, cDNA was synthesized with a High Capacity cDNA Archive kit (Vazyme, Nanjing, China). The PCR reactions were performed on an ABI QuantStudio 6 Flex Real-Time PCR system (Applied Biosystems, Foster City, CA) using Ultra SYBR Mixture (CWBIO). The comparative threshold cycle $(\mathrm{Ct})$ method was used to quantify the fold change $\left(2^{-\Delta \Delta \mathrm{Ct}}\right)$ for various mRNAs, which were normalized to $36 \mathrm{~b} 4 \mathrm{mRNA}$ and presented as relative fold change to the control group. Primer sequences used in this study are summarized in Supplemental Table 2.

Western Blot. Total protein was isolated using RIPA lysis buffer (CWBIO) according to the manufacturer's protocol. Equal amounts of protein samples $(40 \mu \mathrm{g})$ were separated by electrophoresis on $10 \%$ SDS-PAGE and then transferred to polyvinylidene difluoride membranes. The membranes were blocked with $5 \%$ skim milk, followed by overnight incubation with primary antibodies against p65 (1:1000, no. 8242; Cell Signaling Technology, Danvers, MA), c-Jun (1:1000, no. 9165; Cell Signaling Technology), URAT1 (1:500, no. 250521; Abbiotec, San Diego, CA), and $\beta$-actin (1:1500, K101527P; Solarbio, Beijing, China). Blots were then further incubated with secondary antibody (1:5000, sc-2004; Santa Cruz, Dallas, TX) in 5\% skim milk, and signals were visualized with enhanced chemiluminescence reagents (Merck Millipore, Darmstadt, Germany). Images were visualized by the Amersham Imager 600 (GE Healthcare, Pittsburgh, PA) and analyzed using Image J software (National Institutes of Health, Bethesda, MA).

Data Analysis and Statistics. Data were analyzed using GraphPad Prism software version 7.0. (GraphPad, San Diego, CA) and expressed as means \pm S.E.M. The differences between groups were analyzed using ANOVA, followed by two-by-two comparisons using Tukey's test. $P<0.05$ was considered significant.

\section{Results}

$10,000 \mathrm{~g}$ for 10 minutes at $4^{\circ} \mathrm{C}$, and the final supernatant was collected for the assays. Protein concentration of the final supernatant was determined with the bicinchoninic acid (BCA) method according to the manufacturer's instructions (CWBIO, Beijing, China). To determine the XOD activity, XOD standard solutions were prepared by diluting XOD stock in $50 \mathrm{mM} \mathrm{KH}_{2} \mathrm{PO}_{4}$ buffer containing $0.5 \mathrm{mM}$ EDTA ( $\mathrm{pH} 7.4$ ). Subsequently, a mixture of $25 \mu \mathrm{l}$ of substrate solution (1.5 mM xanthine, $1.0 \mathrm{mM}$ potassium oxonate in $0.02 \mathrm{M} \mathrm{NaOH}), 25 \mu \mathrm{l}$ of liver extract or XOD standard solution, and $150 \mu \mathrm{l}$ of $\mathrm{KH}_{2} \mathrm{PO}_{4}$ buffer $(50 \mathrm{mM})$ were loaded into a 96 -well plate and incubated at $37^{\circ} \mathrm{C}$ for 30 minutes. The absorbance of UA production was read at $294 \mathrm{~nm}$. To determine uricase activity, liver extract was incubated with $30 \mu \mathrm{M}$ UA in $50 \mathrm{mM}$ borate buffer ( $\mathrm{pH}$ 9.0) at $37^{\circ} \mathrm{C}$ for 30 minutes. The decrease of UA was determined by the decrease of absorption at $294 \mathrm{~nm}$.

Cell Culture and Treatment. Normal rat kidney epithelial cells (NRK-52E) were obtained from cell resource center of Shanghai Institutes for Biologic Sciences (Shanghai, China). Cells were cultured with Dulbecco's modified Eagle's medium (DMEM) high-glucose medium supplemented with $10 \%$ fetal bovine serum (FBS), $100 \mathrm{U} / \mathrm{ml}$ penicillin and $100 \mu \mathrm{g} / \mathrm{ml}$ streptomycin at $37^{\circ} \mathrm{C}$ in $5 \% \mathrm{CO}_{2}$. The chemicals were dissolved in DMSO. Cells were seeded in triplicate in 24 -well plates at a density of $2.5 \times 10^{5} /$ well and allowed to attach overnight. Twenty-four hours after plating, DEX, TA, and MIF diluted in fresh DMEM containing 5\% FBS were added. The final concentrations of DEX, TA, and MIF were $1,0.5$, and $0.15 \mu \mathrm{M}$, respectively, as previously described (Bradley and Mishell, 1981; Ray and Prefontaine, 1994; Boonyaratanakornkit

\section{DEX, but Not NSAIDs, Markedly Altered UA Homeostasis in} Mice. As shown in Fig. 1, A and B, three NSAIDs had no effect on UA concentrations in serum or livers of mice. Additionally, the activities of XOD and uricase, as well as the mRNA levels of key enzymes involved in UA synthesis, were not altered by NSAID treatments (data not shown). In contrast, both 1 and $5 \mathrm{mg} / \mathrm{kg}$ doses of DEX significantly decreased serum UA $(15 \%-19 \% \downarrow)$ but significantly increased hepatic UA (29\%-36\% $\uparrow$ ), compared with control mice (Fig. 1, C and D). Further analysis demonstrated that both doses of DEX significantly increased urine volume collected for 24 hours on the 2nd (69\% and 100\% $\uparrow$ ), 4th (90\% and 170\% $\uparrow$ ), and 6th (50\% and 69\% $\uparrow$ ) day of treatment (Fig. 1E). Additionally, as shown in Fig. 1F, DEX also significantly increased the 3 -day cumulative UA excretion $(56 \%$ and $77 \% \uparrow$ for 1 and $5 \mathrm{mg} / \mathrm{kg}$, respectively).

DEX Increased UA Synthesis in Livers of Mice via XOR Induction. The mRNA levels of key enzymes involved in UA synthesis were quantified to investigate the mechanism for DEX-mediated increase of UA in the livers of mice. DEX had no effect on the mRNA levels of phosphoribosyl amidotransferase, phosphoribosyl pyrophosphate synthetase, adenosine deaminase, and hypoxanthine-guanine 

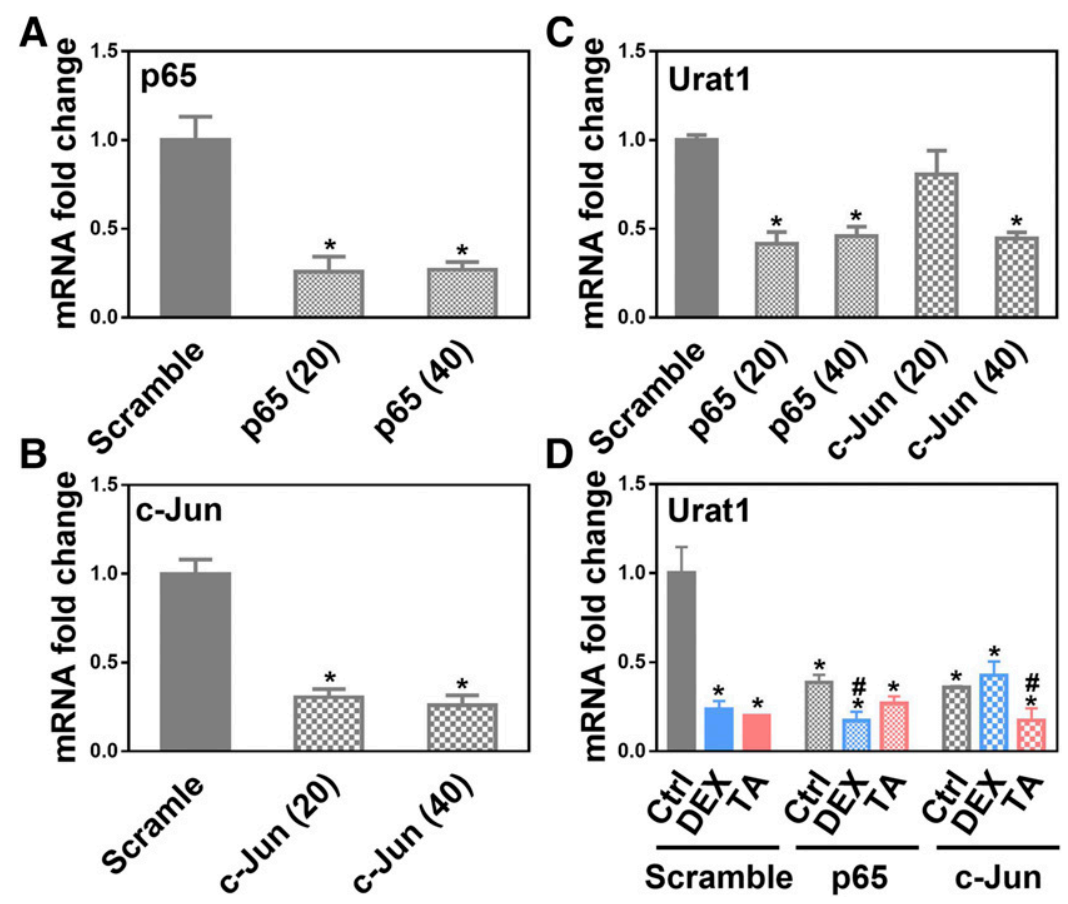

Fig. 6. Both NF- $\kappa \mathrm{B}$ and c-Jun are involved in GR-mediated regulation of URAT1 in vitro. NRK-52E cells were transfected with siRNAs (20 and $40 \mathrm{nM}$ ) to knock down the mRNA levels of either p65 (A) or c-Jun (B). Their effects on URAT1 mRNA expression (C) were determined. NRK-52E cells were transfected with either p65 siRNAs or c-Jun siRNAs $(40 \mathrm{nM})$ for 24 hours and then cotreated with either DEX $(1 \mu \mathrm{M})$ or TA $(0.5 \mu \mathrm{M})$ for additional 24 hours. The mRNA levels of URAT1 were quantified using RT-PCR (D). Data are expressed as mean \pm S.E.M. $* P<0.05$ vs. scramble siRNA control. ${ }^{\#} P<0.05$ vs. p65 siRNA control (Ctrl) or c-Jun siRNA control (Ctrl).

phosphoribosyltransferase (Fig. 2A). UA in the livers of mice is regulated mainly by the activities of XOD (key enzyme in UA synthesis) and uricase (enzyme for UA oxidization). DEX significantly increased XDH mRNA levels in a dose-dependent manner ( $26 \%$ and $110 \% \uparrow$ for 1 and $5 \mathrm{mg} / \mathrm{kg}$, respectively), whereas it had no effect on uricase mRNA levels. Consistently, both doses of DEX significantly increased XOD activity $(61 \%$ and $160 \% \uparrow)$, whereas they did not alter uricase activity in the livers of mice (Fig. 2, B and C). To conclude, the current data suggest that DEX has an inductive effect on XDH mRNA expression and thus increases UA synthesis in the livers of mice.

DEX Decreased Both mRNA and Protein Levels of URAT1 in Kidneys of Mice. Organic anion transporter 1 and 3 (Oat1 and 3) are basolateral UA uptake transporters. DEX had no effect on the mRNA expression of Oat1, but it significantly decreased the mRNA expression of Oat3 (52\% and $81 \% \downarrow$ for 1 and $5 \mathrm{mg} / \mathrm{kg}$, respectively) in a dosedependent manner (Fig. 3A). Breast cancer resistance protein (BCRP), multidrug resistance protein 4 (Mrp4), as well as sodium-dependent phosphate cotransporter type 1 and 4 (Npt1 and 4) are apical UA efflux transporters involved in renal secretion of UA. DEX did not alter BCRP or Mrp4 mRNA levels, whereas it significantly increased the mRNA levels of Npt1 (72\% and $47 \% \uparrow)$ and $4(99 \%$ and $65 \% \uparrow$ for 1 and $5 \mathrm{mg} / \mathrm{kg}$, respectively). Oat10, glucose transporter 9 (Glut9), and URAT1 are apical UA uptake transporters that play a critical role in UA reabsorption. DEX showed no effect on Oat 10 and Glut 9 , but it significantly decreased URAT1 mRNA levels (40\% and 44\% $\downarrow$ for 1 and $5 \mathrm{mg} / \mathrm{kg}$, respectively) in a dose-dependent manner (Fig. 3B). Consistently, both doses of DEX significantly decreased the protein levels of URAT1 in the kidneys of mice (37\% and 45\% $\downarrow$ ) (Fig. 3C). Therefore, the current data suggest that DEX appears to increase UA secretion (Npt1 and 4) and decrease UA reabsorption (URAT1) in the kidneys of mice.

DEX-Mediated Regulation of UA Homeostasis Was Not Due to PXR Signaling Pathway. DEX at higher doses $(>20 \mathrm{mg} / \mathrm{kg})$ is known to activate PXR in mice (Xie et al., 2000), whereas lower doses $(<6 \mathrm{mg} / \mathrm{kg})$ mainly activate glucocorticoid receptor (GR) signaling (Heuman et al., 1982). Both 1 and $5 \mathrm{mg} / \mathrm{kg}$ of DEX significantly increased the GR target gene serum- and glucocorticoid-induced protein kinase 1 (Sgk1) in the livers (23-fold and 20-fold $\uparrow$ ) and kidneys (12-fold and 14-fold $\uparrow$ ) of mice, suggesting the activation of GR signaling pathway (Fig. 4A). To determine the effect of PXR activation on UA homeostasis, mice were given either a high dose of DEX (75 mg/kg) or PCN, a well known PXR agonist. Both $75 \mathrm{mg} / \mathrm{kg}$ DEX and PCN significantly increased mRNA levels of the PXR target gene cytochrome P450 3a11 (Cyp3a11) in the livers of mice (33-fold and 27-fold $\uparrow$ ), suggesting the activation of the PXR pathway (Fig. 4B); however, neither $75 \mathrm{mg} / \mathrm{kg}$ DEX nor PCN altered the UA concentrations, $\mathrm{XDH}$ mRNA, or XOD activity in the livers of mice (Fig. 4, $\mathrm{C}-\mathrm{E})$. Therefore, GR activation, but not PXR activation, mediates the effect of DEX on hepatic UA levels in mice.

GR Regulated DEX-Mediated Downregulation of URAT1 in Vitro. NRK-52E cells were treated with DEX and TA, two GR agonists, to determine the role of GR in URAT1 regulation. The activation of GR by DEX and triamcinolone acetonide (TA) was demonstrated by the increased mRNA levels of Sgk1 (3.3-fold and 5.2-fold $\uparrow$ for 1 and $5 \mathrm{mg} / \mathrm{kg}$, respectively) (Fig. 5A). Both mRNA and protein levels of URAT1 were significantly decreased by DEX (mRNA 63\% $\downarrow$; protein $38 \% \downarrow$ ) and TA (mRNA 59\% $\downarrow$; protein 57\% $\downarrow$ ) (Fig. 5, B and C). Notably, GR antagonist MIF reversed the downregulating effect of DEX and TA on URAT1 mRNA expression (D + M vs. DEX, 97\% ; $\mathrm{T}+\mathrm{M}$ vs. TA, 77\% $\uparrow$ ) (Fig. 5C). Additionally, GR knockdown by siRNA ablated the downregulating effect of DEX and TA on URAT1 (Fig. 5D). It should be mentioned that both MIF and GR knockdown significantly increased the mRNA levels of URAT1 (MIF, 47\% $\uparrow$; GR knockdown, 190\% (Fig. 5, C and D). Collectively, the current data suggest that GR signaling pathway plays a critical role in regulating URAT1 in kidney cells.

Both Nuclear Factor $\kappa B$ and c-Jun Were Involved in GR-Mediated Regulation of URAT1 In Vitro. GR-dependent transcriptional regulation depends on its interaction with other coregulatory proteins. In silico analysis suggests that the URAT1 promoter region contained several putative nuclear factor (NF) $-\kappa \mathrm{B}$ and activator protein 1 (AP-1) binding sites (Table 1). Next, NF- $\kappa \mathrm{B} / \mathrm{p} 65$ or AP-1/c-Jun was knocked down in NRK-52E cells to investigate the role of NF- $\kappa$ B and AP-1 in URAT1 regulation. Both 20 and $40 \mathrm{nM}$ p65 siRNA significantly decreased mRNA levels of p65 (20 nM, 74\% $\downarrow$; $40 \mathrm{nM}, 73 \% \downarrow)$ and URAT1 (20 nM, 59\% $\downarrow$; $40 \mathrm{nM}, 54 \% \downarrow$ ) (Fig. 6, A and C). Similarly, c-Jun mRNA 
A

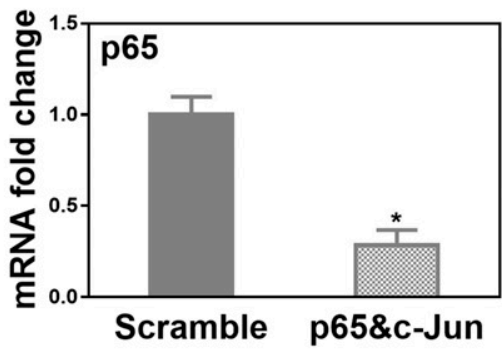

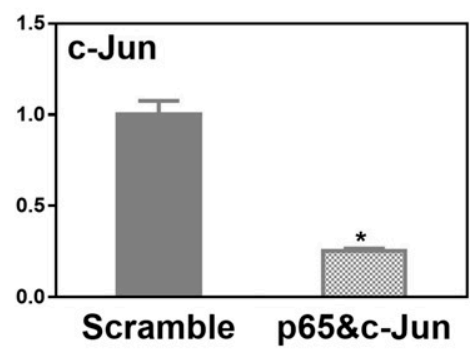

B
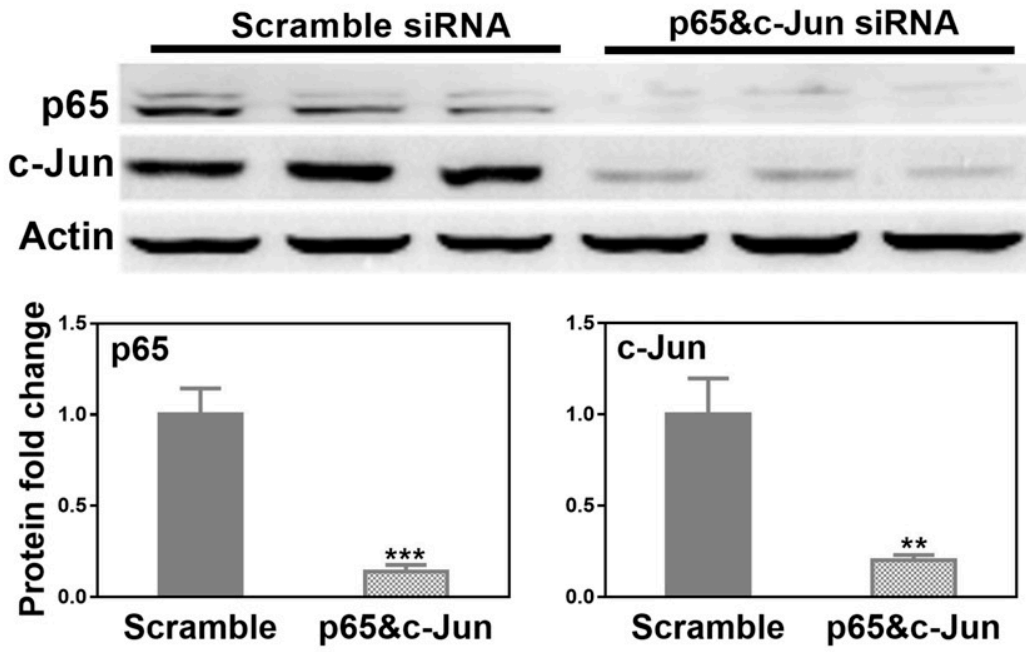

C
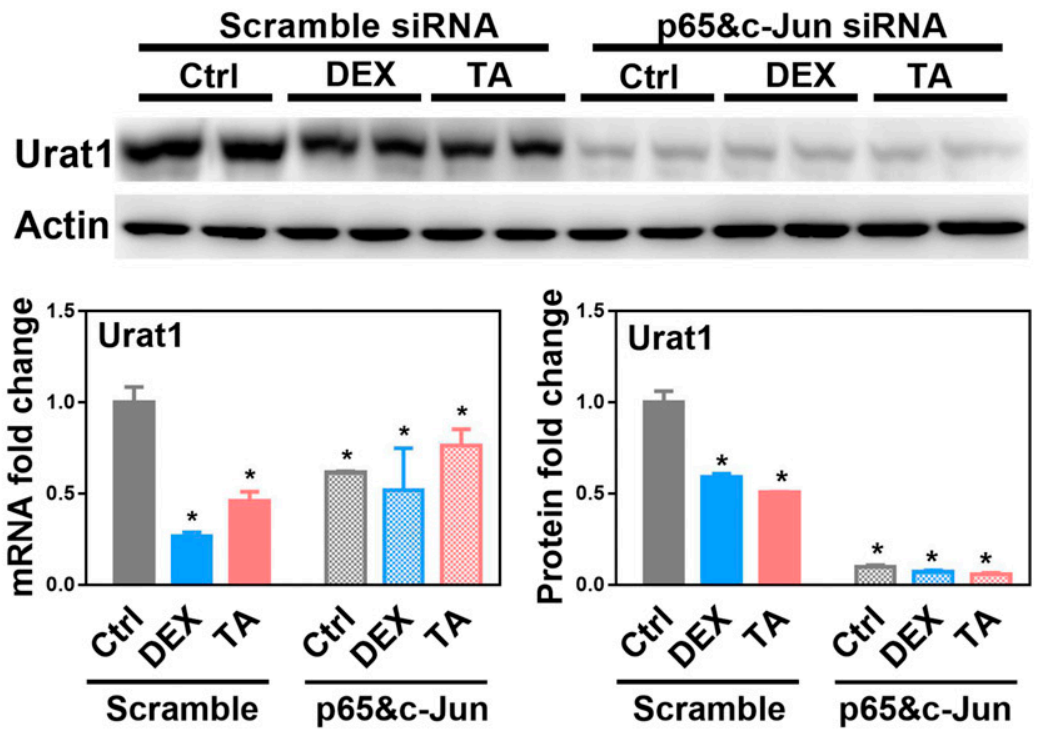

Fig. 7. Knockdown of both p65 and c-Jun completely blocked the downregulating effect of GR activation on URAT1 in vitro. NRK-52E cells were cotransfected with both $\mathrm{p} 65$ and c-Jun siRNAs to knock down their mRNA expression (A). The protein levels of p65 and c-Jun were also quantified using Western blot after cotransfection of siRNAs (B). NRK-52E cells were cotransfected with both p65 and c-Jun siRNAs for 24 hours and then were cotreated with either DEX $(1 \mu \mathrm{M})$ or TA $(0.5 \mu \mathrm{M})$ for additional 24 hours. The mRNA and protein levels of URAT1 were quantified (C). Data are expressed as means \pm S.E.M. $* P<0.05$ vs. sramble siRNA control; $* * P<0.01$ vs. scramble siRNA control; $* * * P<0.001$ vs. scramble siRNA control. levels were significantly decreased by both $20(69 \% \downarrow)$ and $40 \mathrm{nM}$ (74\% $\downarrow$ ) c-Jun siRNA treatments (Fig. 6B); however, only $40 \mathrm{nM}$ c-Jun siRNA was able to decrease URAT1 mRNA levels (55\% $\downarrow$ ) (Fig. 6C). Thus, $40 \mathrm{nM}$ p65 and c-Jun siRNA were used in the subsequent treatments, showing that neither p65 knockdown nor c-Jun knockdown was able to prevent completely the downregulating effects of DEX and TA in kidney cells (Fig. 6D). To conclude, the current data suggest that both p65 and c-Jun play an important role in maintaining the basal level of URAT1 and are partly involved in GR-mediated downregulation of URAT1 mRNA expression.

Knockdown of Both p65 and c-Jun Completely Blocked the Downregulating Effect of GR Activation on URAT1 In Vitro. To investigate further the role of p65 and c-Jun on GR-mediated regulation of URAT1, both p65 and c-Jun were knocked down in NRK-52E cells. The decreased mRNA (p65, 71\% (p65, 85\% $\downarrow$; c-Jun, $80 \% \downarrow$ ) of p65 and c-Jun validated the knockdown effect of siRNA treatments (Fig. 7, A and B). The knockdown of both p65 and c-Jun completely reversed the downregulating effect of DEX and TA on both mRNA and protein levels of URAT1 (Fig. 7C). Therefore, the current data suggests that GR-mediated regulation of URAT1 is dependent on both p65 and c-Jun.

\section{Discussion}

Despite the wide use of NSAIDs and glucocorticoids in gout treatment, their effects on UA metabolism are poorly investigated. Our 
data suggest that oral administration with high doses of NSAIDs causes adverse effects in both the liver and intestine of mice. According to both literature and preliminary studies, we treated mice with each NSAID at a dose that is relatively close to the maximum nontoxic dose and demonstrated that the three NSAIDs at therapeutic doses had no effect on UA homeostasis. In contrast, DEX significantly altered UA concentrations in mice by increasing both the production and elimination of UA.

$\mathrm{XOR}$ is the rate-limiting enzyme catalyzing the conversion from hypoxanthine to xanthine and from xanthine to UA in the liver. Various stimuli, such as hydrogen peroxide, calcium, growth factors, and inflammatory cytokines, are able to regulate XOR expression and activity (Dupont et al., 1992; Flanders et al., 1997; McNally et al., 2005). Previous studies demonstrated that DEX could induce XOR expression and activity in bovine epithelial cells and rat cremaster muscle (Pfeffer et al., 1994; Wallwork et al., 2003). The current data demonstrate an inductive effect of DEX on both expression and activity of XOR in livers of mice, which was associated with an increase in hepatic UA.

Nuclear receptors play an important role in regulating various physiologic processes. Aryl hydrocarbon receptor and peroxisome proliferator-activated receptor $\alpha$ have been implicated in regulating XOR (Sugihara et al., 2001; Kanemitsu et al., 2017). PXR is a key regulator of xenobiotic metabolism and is activated by a broad range of endogenous and exogenous chemicals, such as bile acids, steroids, and antibiotics (Kliewer et al., 2002). Glucocorticoids are also able to activate the PXR signaling pathway at high doses (Xie et al., 2000). Nonetheless, the present study demonstrated that DEX-mediated induction of XOR was due to the activation of GR, but not PXR. It should be noted that we did not quantify the serum levels of UA or the mRNA levels of urate transporters in kidneys. Therefore, it could not be excluded that high-dose DEX could still affect UA distribution. Nonetheless, the present study suggests that PXR activation has no effect on hepatic UA concentrations, XDH activities, or mRNA levels of UA-related genes (Supplemental Fig. 3) in mice.

The present study demonstrated that DEX significantly increased renal excretion of UA and thus decreased serum UA, despite the increased UA production in the liver. The kidney accounts for about $60 \%-65 \%$ of the daily elimination of UA (Sorensen, 1965). UA in the circulation is freely filtered by the glomerulus, and more than $90 \%$ of UA is reabsorbed in the proximal tubule. Additionally, tubular secretion of UA also occurs. Both UA reabsorption and secretion involve many membrane transporters (Hyndman et al., 2016). During the tubular secretion, UA is taken up by Oat1 and 3 from the blood into the kidney and transported into urine through efflux transporters such as Ntp1, Npt4, Mrp4, and BCRP. Although DEX increased Ntp1 and 4, it markedly decreased Oat 3 in the kidneys of mice, suggesting a mixed effect of DEX on UA secretion. Nonetheless, compared with UA reabsorption, the tubular secretion is only a minor component of urine UA excretion. Among three transporters (URAT1, Glut9, and Oat10) involved in UA reabsorption, only URAT1 was significantly decreased by DEX. Therefore, DEX-mediated increase in urine UA excretion is due mainly to its downregulating effect on URAT1.

URAT1 is considered the most effective transporter in the reabsorption of UA, and its abundance is closely linked to serum UA concentration (Köttgen et al., 2013). Although URAT1 has become the therapeutic target for lowering UA, its regulatory mechanism remains largely unknown. In the present study, GR agonist decreased, whereas GR antagonist or knockdown increased URAT1. Additionally, GR knockdown completely blocked the inhibitory effect of DEX on URAT1, suggesting a critical role of GR in regulating URAT1. In silico analysis reveal that URAT1 promoter has several putative NF- $\kappa \mathrm{B}$ and AP-1 binding sites. Previous studies reported that the direct interaction between NF- $\kappa$ B and GR-mediated repression of interleukins by DEX (Ray and Prefontaine, 1994). Similarly, a direct interaction between GR and c-Jun was also reported in previous studies (Schule et al., 1990; Yang-Yen et al., 1990). In the present study, either p65 or c-Jun knockdown markedly decreased URAT1, suggesting an important role of p65 and c-Jun in maintaining the basal level of URAT1; however, only knockdown of both p65 and c-Jun could completely prevent the downregulation of URAT1 by DEX and TA, suggesting that GRmediated regulation of URAT1 requires the interaction of both p65 and c-Jun. It is reported that in vitro knockdown of GR by RNA interference could enhance the basal NF-kB activity (Zhu et al., 2004). This finding may explain the increased basal mRNA level of URAT1 in GR knockdown cells in this study. Therefore, the current data suggest that DEX downregulates URAT1 through the GR-mediated interaction of both NF-kB and AP-1.

It should be noted that the present study is limited by considerable species differences in UA metabolism between humans and mice. For instance, UA is metalized to allantoin by uricase in the livers of mice, whereas it is the end product of purine metabolism in humans owing to the loss of uricase activity during evolution (Oda et al., 2002). Although transporters such as URAT1, BCRP, OATs, and NPTs are expressed in the kidneys of both humans and mice, their abilities in handling UA might differ (Hosomi et al., 2012). Nevertheless, the current findings demonstrate for the first time that glucocorticoids play an important role in regulating UA homeostasis via GR signaling pathway. In the liver, GR activation induces XOR expression and activity and thus elevates UA production. In the kidney, GR activation downregulates both mRNA and protein levels of URAT1 through NF-kB and AP-1 and thus enhances UA excretion in the urine.

\section{Authorship Contribution}

Participated in research design: $\mathrm{Li}, \mathrm{Lu}$, Zhang.

Conducted experiments: Li, Ma, Saeed, Xiong.

Contributed new reagents or analytic tools: Han, Zhang.

Performed data analysis: Li, Han, Zhang.

Wrote or contributed to the writing of the manuscript: Li, Klaassen, Lu, Zhang.

\section{References}

Akingbasote JA, Foster AJ, Wilson I, Sarda S, Jones HB, and Kenna JG (2016) Hepatic effects of repeated oral administration of diclofenac to hepatic cytochrome $\mathrm{P} 450$ reductase null $\left(\mathrm{HRN}^{\mathrm{TM}}\right)$ and wild-type mice. Arch Toxicol 90:853-862.

Ban K, Santora R, and Kozar RA (2011) Enteral arginine modulates inhibition of AP-1/c-Jun by SP600125 in the postischemic gut. Mol Cell Biochem 347:191-199.

Boonyaratanakornkit V, Melvin V, Prendergast P, Altmann M, Ronfani L, Bianchi ME, Taraseviciene L, Nordeen SK, Allegretto EA, and Edwards DP (1998) High-mobility group chromatin proteins 1 and 2 functionally interact with steroid hormone receptors to enhance their DNA binding in vitro and transcriptional activity in mammalian cells. Mol Cell Biol 18:4471-4487.

Bradley LM and Mishell RI (1981) Differential effects of glucocorticosteroids on the functions of helper and suppressor T lymphocytes. Proc Natl Acad Sci USA 78:3155-3159.

Dalbeth N, Merriman TR, and Stamp LK (2016) Gout. Lancet 388:2039-2052.

Dupont GP, Huecksteadt TP, Marshall BC, Ryan US, Michael JR, and Hoidal JR (1992) Regulation of xanthine dehydrogenase and xanthine oxidase activity and gene expression in cultured rat pulmonary endothelial cells. J Clin Invest 89:197-202.

Enomoto A, Kimura H, Chairoungdua A, Shigeta Y, Jutabha P, Cha SH, Hosoyamada M, Takeda M, Sekine T, Igarashi T, et al. (2002) Molecular identification of a renal urate anion exchanger that regulates blood urate levels. Nature 417:447-452.

Flanders KC, Bhandiwad AR, and Winokur TS (1997) Transforming growth factor-betas block cytokine induction of catalase and xanthine oxidase mRNA levels in cultured rat cardiac cells. J Mol Cell Cardiol 29:273-280

Fujiyoshi T, Kuwashima M, Iida H, and Uematsu T (1989) A new writhing model of factor XII activator-induced pain for assessment of non-steroidal anti-inflammatory agents. I Kaolin-induced writhing in mice. J Pharmacobiodyn 12:132-136.

Harusato A, Naito Y, Takagi T, Yamada S, Mizushima K, Hirai Y, Horie R, Inoue K, Fukumoto K, Hirata I, et al. (2009) Inhibition of Bach1 ameliorates indomethacin-induced intestinal injury in mice. J Physiol Pharmacol 60 (Suppl 7):149-154.

Heuman DM, Gallagher EJ, Barwick JL, Elshourbagy NA, and Guzelian PS (1982) Immunochemical evidence for induction of a common form of hepatic cytochrome P-450 in rats treated with pregnenolone-16 alpha-carbonitrile or other steroidal or non-steroidal agents. Mol Pharmacol 21:753-760.

Hosomi A, Nakanishi T, Fujita T, and Tamai I (2012) Extra-renal elimination of uric acid via intestinal efflux transporter BCRP/ABCG2. PLoS One 7:e30456. 
Hyndman D, Liu S, and Miner JN (2016) Urate handling in the human body. Curr Rheumatol Rep 18:34

Jenkins WL (1987) Pharmacologic aspects of analgesic drugs in animals: an overview. J Am Vet Med Assoc 191:1231-1240.

Kanemitsu T, Tsurudome Y, Kusunose N, Oda M, Matsunaga N, Koyanagi S, and Ohdo S (2017) Periodic variation in bile acids controls circadian changes in uric acid via regulation of xanthine oxidase by the orphan nuclear receptor PPAR $\alpha$. J Biol Chem 292:21397-21406.

Kim KS, Baek SJ, Flake GP, Loftin CD, Calvo BF, and Eling TE (2002) Expression and regulation of nonsteroidal anti-inflammatory drug-activated gene (NAG-1) in human and mouse tissue. Gastroenterology 122:1388-1398.

Kliewer SA, Goodwin B, and Willson TM (2002) The nuclear pregnane X receptor: a key regulator of xenobiotic metabolism. Endocr Rev 23:687-702.

Klopcic B, Appelbee A, Raye W, Lloyd F, Jooste JC, Forrest CH, and Lawrance IC (2008) Indomethacin and retinoic acid modify mouse intestinal inflammation and fibrosis: a role for SPARC. Dig Dis Sci 53:1553-1563.

Köttgen A, Albrecht E, Teumer A, Vitart V, Krumsiek J, Hundertmark C, Pistis G, Ruggiero D, O'Seaghdha CM, Haller T, et al.; LifeLines Cohort Study; ; CARDIoGRAM Consortium; ; DIAGRAM Consortium; ; ICBP Consortium; ; MAGIC Consortium (2013) Genome-wide association analyses identify 18 new loci associated with serum urate concentrations. Nat Genet $\mathbf{4 5}$ $145-154$.

Kratzer JT, Lanaspa MA, Murphy MN, Cicerchi C, Graves CL, Tipton PA, Ortlund EA, Johnson RJ, and Gaucher EA (2014) Evolutionary history and metabolic insights of ancient mammalian uricases. Proc Natl Acad Sci USA 111:3763-3768.

Kuo TM, Huang CM, Tu HP, Min-Shan Ko A, Wang SJ, Lee CP, and Ko YC (2017) URAT1 inhibition by ALPK1 is associated with uric acid homeostasis. Rheumatology (Oxford) 56: 654-659.

Liles JH and Flecknell PA (1992) The use of non-steroidal anti-inflammatory drugs for the relief of pain in laboratory rodents and rabbits. Lab Anim 26:241-255.

Maiuolo J, Oppedisano F, Gratteri S, Muscoli C, and Mollace V (2016) Regulation of uric acid metabolism and excretion. Int J Cardiol 213:8-14.

McNally JS, Saxena A, Cai H, Dikalov S, and Harrison DG (2005) Regulation of xanthine oxidoreductase protein expression by hydrogen peroxide and calcium. Arterioscler Thromb Vasc Biol 25:1623-1628.

Mount DB (2005) Molecular physiology and the four-component model of renal urate transport. Curr Opin Nephrol Hypertens 14:460-463.

Mun SH, Kim HS, Kim JW, Ko NY, Kim DK, Lee BY, Kim B, Won HS, Shin H-S, Han J-W, et al. (2009) Oral administration of curcumin suppresses production of matrix metalloproteinase (MMP)-1 and MMP-3 to ameliorate collagen-induced arthritis: inhibition of the PKCdelta/JNK/ c-Jun pathway. J Pharmacol Sci 111:13-21.

Numakawa T, Kumamaru E, Adachi N, Yagasaki Y, Izumi A, and Kunugi H (2009) Glucocorticoid receptor interaction with TrkB promotes BDNF-triggered PLC-gamma signaling for glutamate release via a glutamate transporter. Proc Natl Acad Sci USA 106:647-652.

Oda M, Satta Y, Takenaka O, and Takahata N (2002) Loss of urate oxidase activity in hominoids and its evolutionary implications. Mol Biol Evol 19:640-653.

Patel R, Williams-Dautovich J, and Cummins CL (2014) Minireview: new molecular mediators of glucocorticoid receptor activity in metabolic tissues. Mol Endocrinol 28:999-1011.

Pfeffer KD, Huecksteadt TP, and Hoidal JR (1994) Xanthine dehydrogenase and xanthine oxidase activity and gene expression in renal epithelial cells: cytokine and steroid regulation. J Immunol 153:1789-1797.

Ragab G, Elshahaly M, and Bardin T (2017) Gout: an old disease in new perspective - a review. $J$ Adv Res 8:495-511.

Ray A and Prefontaine KE (1994) Physical association and functional antagonism between the p65 subunit of transcription factor NF-kappa B and the glucocorticoid receptor. Proc Natl Acad Sci USA 91:752-756.
Ritesh C, Pooja S, Savita V, Hemant T, and Shubham A (2016) Analgesic activity of cinnamaldehyde per se and it's interaction with diclofenac sodium and pentazocine in swiss albino mice. Int J Pharm 3:97-102.

Schüle R, Rangarajan P, Kliewer S, Ransone LJ, Bolado J, Yang N, Verma IM, and Evans RM (1990) Functional antagonism between oncoprotein c-Jun and the glucocorticoid receptor. Cell 62:1217-1226.

Sirabella R, Secondo A, Pannaccione A, Scorziello A, Valsecchi V, Adornetto A, Bilo L, Di Renzo G, and Annunziato L (2009) Anoxia-induced NF-kappaB-dependent upregulation of NCX1 contributes to $\mathrm{Ca} 2+$ refilling into endoplasmic reticulum in cortical neurons. Stroke 40:922-929. Sorensen LB (1965) Role of the intestinal tract in the elimination of uric acid. Arthritis Rheum $\mathbf{8}$ : 694-706.

Sugihara K, Kitamura S, Yamada T, Ohta S, Yamashita K, Yasuda M, and Fujii-Kuriyama Y (2001) Aryl hydrocarbon receptor (AhR)-mediated induction of xanthine oxidase/xanthine dehydrogenase activity by 2,3,7,8-tetrachlorodibenzo-p-dioxin. Biochem Biophys Res Commun 281:1093-1099.

Tin A, Li Y, Brody JA, Nutile T, Chu AY, Huffman JE, Yang Q, Chen MH, Robinson-Cohen C, Macé A, et al. (2018) Large-scale whole-exome sequencing association studies identify rare functional variants influencing serum urate levels. Nat Commun 9:4228-4238.

Toyoki D, Shibata S, Kuribayashi-Okuma E, Xu N, Ishizawa K, Hosoyamada M, and Uchida S (2017) Insulin stimulates uric acid reabsorption via regulating urate transporter 1 and ATPbinding cassette subfamily G member 2. Am J Physiol Renal Physiol 313:F826-F834.

Tsushima Y, Nishizawa H, Tochino Y, Nakatsuji H, Sekimoto R, Nagao H, Shirakura T, Kato K, Imaizumi K, Takahashi H, et al. (2013) Uric acid secretion from adipose tissue and its increase in obesity. J Biol Chem 288:27138-27149.

Wallwork CJ, Parks DA, and Schmid-Schönbein GW (2003) Xanthine oxidase activity in the dexamethasone-induced hypertensive rat. Microvasc Res 66:30-37.

Wang JP, Ho TF, Lin CN, and Teng CM (1994) Effect of norathyriol, isolated from Tripterospermum lanceolatum, on A23187-induced pleurisy and analgesia in mice. Naunyn Schmiedebergs Arch Pharmacol 350:90-95.

Xiao X, Nakatsu G, Jin Y, Wong S, Yu J, and Lau JY (2017) Gut microbiota mediates protection against enteropathy induced by indomethacin. Sci Rep 7:40317.

Xie W, Barwick JL, Downes M, Blumberg B, Simon CM, Nelson MC, Neuschwander-Tetri BA, Brunt EM, Guzelian PS, and Evans RM (2000) Humanized xenobiotic response in mice expressing nuclear receptor SXR. Nature 406:435-439.

Yamada S, Naito Y, Takagi T, Mizushima K, Hirai Y, Horie R, Fukumoto K, Inoue K, Harusato A Yoshida N, et al. (2011) Reduced small-intestinal injury induced by indomethacin in interleukin17A-deficient mice. J Gastroenterol Hepatol 26:398-404

Yang-Yen HF, Chambard JC, Sun YL, Smeal T, Schmidt TJ, Drouin J, and Karin M (1990) Transcriptional interference between c-Jun and the glucocorticoid receptor: mutual inhibition of DNA binding due to direct protein-protein interaction. Cell 62:1205-1215.

Zhang Y, Neogi T, Chen C, Chaisson C, Hunter DJ, and Choi H (2014) Low-dose aspirin use and recurrent gout attacks. Ann Rheum Dis 73:385-390.

Zhu XY, Liu YJ, Lu J, and Xu RB (2004) Knockdown of glucocorticoid receptor expression by RNA interference promotes cell proliferation in murine macrophage RAW264.7 cells. J Steroid Biochem Mol Biol 92:375-382.

Address correspondence to: Youcai Zhang, Tianjin University, School of Pharmaceutical Science and Technology, 92 Weijin Road, Nankai District, Tianjin 300072, China. E-mail: youcai.zhang@tju.edu.cn; or Yuanfu Lu, No.6 West Xuefu Road, Xinpu District, Zunyi, Guizhou 563003, China. E-mail: luyuanfu2000@ 163.com 